\title{
Effects of species and sites on metal concentrations in byssal threads of two mytilids
}

\author{
J. S. Jaworski ${ }^{a^{*}}$, J. Karasiński ${ }^{\mathrm{a}}$, E. Bulska and J. M. F. Babarro ${ }^{\mathrm{b}}$ \\ 'Faculty of Chemistry' University of Warsaw,Pasteura1, 02-093 Warsaw, Poland \\ ${ }^{\mathrm{b}}$ Instituto de Investigaciones Marina CSIC, Eduardo Cabello 6, 36208 Vigo, Spain
}

\begin{abstract}
Concentrations of 11 metals (Al, Cu, Fe, Mg, Mn, Mo, Ni, Pb, Sr, Vand Zn) were determined by inductively coupled plasma quadruple mass spectrometer measurements in byssus of two mytilid species Mytilus galloprovincialis and Xenostrobus securis from three sites situated along the coastline of Ría de Vigo (NW Spain). The species coexist only at one of those sites, thus it was possible to compare the impact of both factors, site and species, on metal concentrations. Principal component and regression analyses showed a dominant effect of mussel species and not the site. In all samples, the highest concentration was observed for iron in accordance with the literature data for M. galloprovincialis. One order of magnitude higher concentrations of iron detected in the byssus of $X$. securis than that of $M$. galloprovincialis are discussed considering a different microstructure of byssus threads as shown by transmission electron microscopy images.
\end{abstract}

Keywords: biomonitoring; byssus; trace metals; Mytilus galloprovincialis;

Xenostrobus securis; Rias Gallegas; estuarine environment 
* Corresponding author. Email: jaworski@chem.uw.edu.pl

\section{Introduction}

Byssal threads secreted by marine mussels, particularly by the Mytilidae, the most widespread species in contaminated coastal waters, have been considered as very attractive for biomonitoring trace metals in the estuarine environment [1-3] because they accumulate high amounts of metals. Active elimination of metals from the soft tissues to byssus by a possible 'detoxification' mechanism has even been considered [2]. Thus, the reliability of the use of mytilid byssus as a marker of trace metal pollutants was intensively investigated in the last two decades, resulting in some promising conclusions [4-13].

More recently, it has been experimentally proved that Fe ions are incorporated in the Mytilus galloprovincialis thread cuticle during the secretion of a new thread and not by direct absorption from the surrounding waters [14]. It was also directly demonstrated that the cuticle of M. galloprovincialis threads consists of a homogeneous matrix with distinct nanogranules containing 3,4-dihydroxyphenylalanine (DOPA)-iron complexes [15-17]. These complexes are extremely important for the mechanical properties of the byssus threads of $M$. galloprovincialis, assuring high extensibility of their coating. On the other hand, the uniformly homogeneous structure of the cuticle of Perna canaliculus is responsible for its much lower extensibility [15]. The above-mentioned recent results can suggest an important role of biological structure of threads in the accumulation of particular metal ions from the environment. It should be remembered here that even a tenfold difference in $\mathrm{Zn}$ concentrations in the bodies of two species collected from the same location was reported [18]. However, many different factors influence analytical results in a very complex way. Thus, in recent years the use of byssal threads alone as metal biomarkers has not been recommended. Instead, the European Community in the Directive on marine environmental strategy [19] has recommended integral monitoring of the whole ecosystem. According to Annex V of the Directive, it is necessary to develop 'technical specifications and standardised methods for monitoring at Community level' [19]. To meet this challenge, a knowledge of potential relations between metal accumulation in byssus samples and differences in thread microstructure is important so as to avoid misinterpretation of analytical results. Thus, the 
purpose of our work is to study such relations in byssus threads of two mussel species collected at the same time at three different locations, one of them common to both species.

\section{Experimental}

\subsection{Byssus samples}

Three sites of different environmental conditions situated along the coastline of Ría de Vigo (NW Spain) were selected for byssus collection (Figure 1). Two of them - Cabo Estay (CE) and Ensenada of San Simón (SS) - represent outer, exposed and inner, sheltered locations, respectively. They were previously selected to study the effect of site on the mechanical properties and size of byssus of M. galloprovincialis [20]. The third site is Sampaio (SP), located at the mouth of the Oitavén-Verdugo river flowing into the Ria. In addition, following recent investigations of the coexistence of two mytilid species [21,22], the elemental analysis of byssus in our work involved threads secreted by the indigenous and raft cultured mussel $M$. galloprovincialis and by the invasive black pygmy mussel Xenostrobus securis. Both species are present in SS, whereas only $X$. securis is found in SP and M. galloprovincialis only in CE. Thus, it was possible to compare the impact of both factors - site and species - on metal concentrations. Byssal threads were removed with razor blades from the collected mussels whose shells were 30-35 mm long, which was the most frequent length. They were cleaned, rinsed with distilled water and dried. In the case of $M$. galloprovincialis threads, the adhesive plaques were carefully cut off. The byssus secreted by $X$. securis is extremely thin, three times thinner at the proximal part and even five times thinner at the distal part in comparison with byssus of $M$. galloprovincialis, despite a similar size of their shells. However, the number of threads secreted by $X$. securis is even 20 times greater than those secreted by $M$. galloprovincialis. Threads of $X$. securis byssus were easier to remove in wet conditions using a magnifying glass, but the adhesive plaques, clearly visible only under a microscope [21], were not separated from them. 


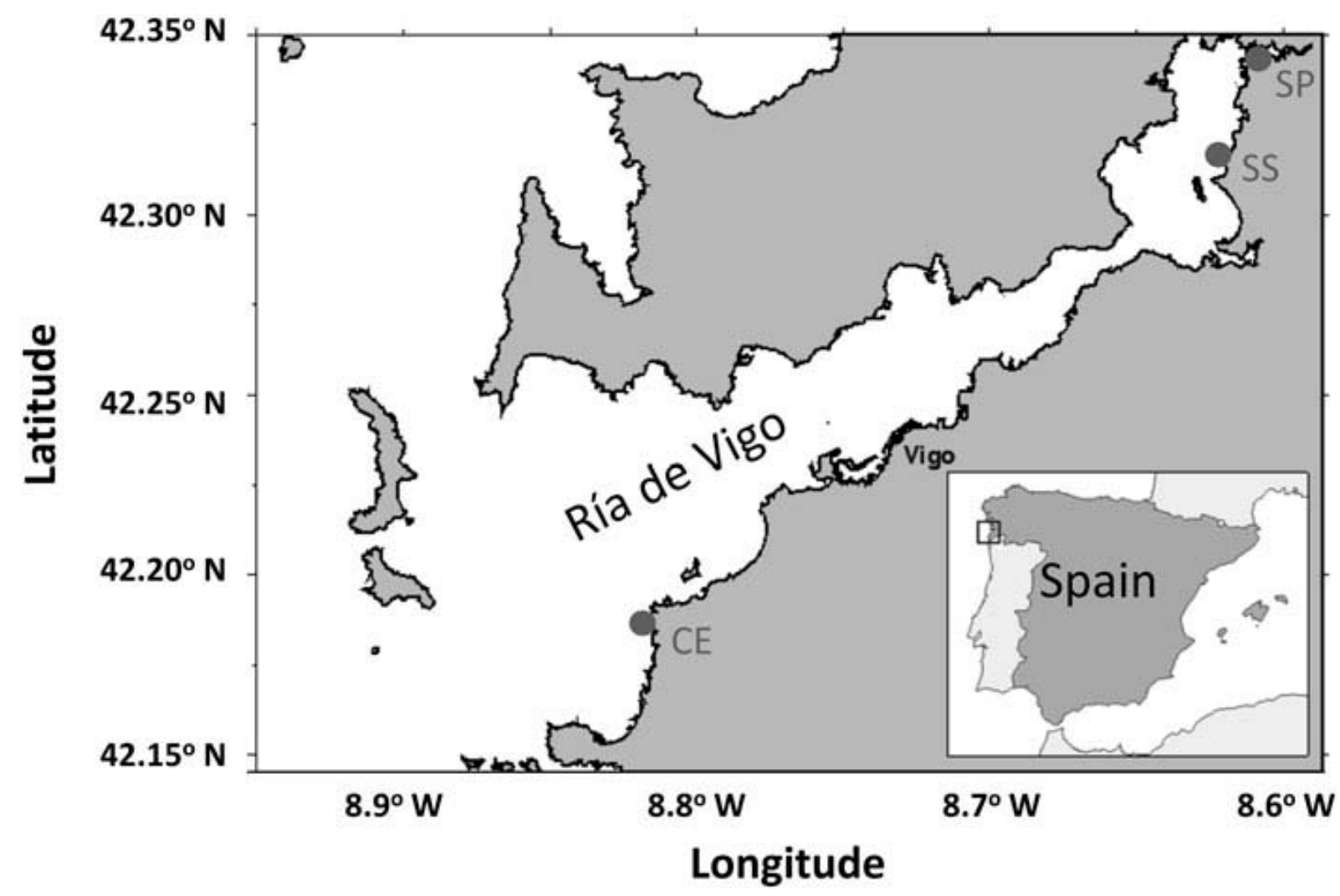

Figure 1. Location of experimental sites in Ría de Vigo (NW Spain): CE, Cabo Estay; SS, San Simón; SP, Sampaio.

\subsection{Sample preparation and ICP-MS measurements}

All dried samples (approximately $30 \mathrm{mg}$ each), after weighing in Teflon vessels and adding about $2 \mathrm{~mL}$ of 65\% nitric acid (Suprapur®, Merck, Germany), were digested in the ultrasonic bath for $24 \mathrm{~h}$ at $50^{\circ} \mathrm{C}$. The obtained solutions were filtered through sterile syringe-driven 0.45 $\mu \mathrm{m}$ polyvinylidene difluoride membrane filters (Millex, France) and then diluted ca. 10 times by weight at room temperature using deionised water from Millipore. Nitric acid solutions treated as above were used as a blank.

An inductively coupled plasma quadruple mass spectrometer (ICP-MS) with dynamic reaction cell (DRC) ELAN 6100 DRC (Perkin-Elmer/Sciex, Canada) was used for the determination of selected elements. The response of the ICP-MS was optimised with a 
standard solution containing $10 \mu \mathrm{g}$ L-1 of $\mathrm{Be}, \mathrm{Mg}$, In, $\mathrm{Ba}, \mathrm{Ce}, \mathrm{Pb}$ and $\mathrm{U}$, respectively. The following analytical conditions were applied: the cyclonic spray chamber, the concentric nebuliser, ICP power of $1050 \mathrm{~W}$, nebuliser gas flow of $0.82 \mathrm{~L}$ min-1, plasma gas flow of $16 \mathrm{~L}$ min-1 and auxiliary gas flow of $1.2 \mathrm{~L}$ min-1. Calibration was performed using the ICP-MS multi-element standard solution VI (Merck, Germany). The accuracy of the results was validated using SRM 1643e (NIST, Canada) and SPS SW 2 (Spectrapure Standards, Norway)-certified reference materials because byssus-certified materials are not available. The SPS SW 2 was selected to mimic noncomplex matrix, similar to that obtained after decomposition of the byssus sample in nitric acid while the SRM 1643e has much more complex matrix specific to natural water. In the case of SPS SW 2, the accuracy for all investigated elements, except iron, was in good agreement with certified values. The relative standard deviation of the results was less than 3\%. For iron, the 30\% signal enhancement has been observed due to the isobaric interferences. Therefore in the last case, the analysis of the recovery was performed. On the basis of SPS SW 2 data and recovery results, the systematic bias was observed. It was decided to overcome this by a mathematical correction. The data obtained with this approach for investigated samples were in agreement with recent literature data [14] as will be discussed later. However, the results for iron could be used only for the relative comparison between the investigated samples in accordance with the purpose of our work.

\subsection{Transmission electron microscopy}

Threads for transmission electron microscopy (TEM) were fixed in 2.5\% glutaraldehyde in cacodylic buffer, incubated for $1 \mathrm{~h}$, then washed with the above buffer, stained with $1 \%$ osmium tetroxide in $\mathrm{D}_{2} \mathrm{O}$ for $1 \mathrm{~h}$ and washed three times with $\mathrm{D}_{2} \mathrm{O}$. The obtained samples were dehydrated through a graded series of aqueous ethanol solutions and infiltrated with epon resin in acetone, infused twice for $1 \mathrm{~h}$ in pure epon resin and polymerised for $24 \mathrm{~h}$ at $60^{\circ} \mathrm{C}$. Thin sections of $70 \mathrm{~nm}$ were prepared and examined using a LEO 912AB (Zeiss, Germany) electron microscope. Micrographs were captured by the Slow Scane CCD (Proscane) using the EsiVision Pro 3.2 software (Soft Imaging Systems GmbH, Germany).

\subsection{Statistical treatment}


Experimental data were processed by the principal component analysis (PCA) using an R statistical software, version 3.1.0 (R Core Team, Wien, Austria, 2014; available at http://www.R-project.org). Input scores were standardised with the mean equal to 0 and the variance equal to 1 . Correlation analysis was performed using a computer program of Dr W. Hyk, University of Warsaw, available at www.e-stat.pl.

\section{Results and discussion}

\subsection{Concentrations of metals}

Concentrations of 11 metals determined in byssal threads of $M$. galloprovincialis and $X$. securis collected at different sites are given in Table 1 . The monitored isotopes of each element are indicated. Limits of quantification (LOQ) were between 1 and $3 \mu \mathrm{g} g-1$ for most elements with the exception of $\mathrm{Al}$ and $\mathrm{Mg}$ ( $\mathrm{LOQ} \approx 20 \mu \mathrm{g}$ g-1), due to the relatively high natural prevalence of these elements and, in the case of Fe (LOQ $\approx 30 \mu \mathrm{g}$ g-1), due to isobaric interferences. In our preliminary determinations, it was found that the concentrations of Ag, $\mathrm{Be}, \mathrm{Bi}, \mathrm{Cd}$ and $\mathrm{Ba}$ were below the LOQ for the byssus samples used. The same was found for Mo in byssus samples of $X$. securis and for Sr for the byssus of M. galloprovincialis from SS (Table 1). None of those elements was taken into account in further determinations. Thus, the final statistical analysis included results for only nine elements ( $\mathrm{Al}, \mathrm{Cu}, \mathrm{Fe}, \mathrm{Mg}, \mathrm{Mn}, \mathrm{Ni}, \mathrm{Pb}$, $\mathrm{V}$ and Zn).

Two observations are evident from the data presented in Table 1. First, in each sample the extremely high concentration of iron was found, particularly for the byssus of $X$. securis. Next in the order was the concentration of aluminium (with the exception of magnesium in one sample). These results are in accordance with the recent literature data [14-17] that reported the formation of complexes of iron with 3,4-dihydroxyphenylalanine (DOPA) in the byssus of M. galloprovincialis and their important effect on thread properties. Moreover, a gradual decrease in total concentrations of iron was found along the thread from the distal to the proximal end, with the highest concentration in the plaque [14]. The concentrations of iron and aluminium in the byssus of $M$. galloprovincialis given in Table 1 are similar to those reported by Sun and Waite despite a different geographical region of byssus collection: 0.3 and $0.2 \mathrm{mg} \mathrm{g-1}$ of Fe in distal and proximal parts of threads, respectively, and $0.2 \mathrm{mg}$ g-1 of Al. The iron concentration was ca. three times higher in the plaques than in the distal part of the thread, whereas the aluminium concentration in the plaques was 3-3.8 times higher than 
in the thread [14]. In our work, the concentrations of Fe and $\mathrm{Al}$ were additionally determined for the samples of $M$. galloprovincialis byssus collected at both sites without cutting off the plaques. The obtained results indicate some error introduced by the presence of plaques: e.g. for samples from $\mathrm{CE}$ the differences in $\mathrm{Al}$ and $\mathrm{Fe}$ concentrations are 3\% and 14\%, respectively. For threads from SS mussels containing the plaques, the Fe concentration was $38 \%$ higher than that shown in Table 1. However, this cannot explain a one order of magnitude higher concentration of $\mathrm{Fe}$ in the byssus of $X$. securis than in that of $M$. galloprovincialis.

Another conclusion that can be drawn from data presented in Table 1 is that much higher concentrations of metals were detected in the byssus of $X$. securis than in the byssus of $M$. galloprovincialis from the same site SS. The concentration was 10.7 times higher for Fe, 9.9 times higher for $\mathrm{Cu}, 5.3$ for $\mathrm{Mg}$ and ca. four times higher for $\mathrm{Pb}, \mathrm{Zn}$ and $\mathrm{Al}$. These results evidently show a higher ability to bind metal cations by the byssus of $X$. securis, suggesting that the choice of a species for biomonitoring is very important. The different values of the concentration ratio for different elements (Table 1) also indicate that the use of byssus as biomonitors can lead to serious errors.

\subsection{Statistical analysis}

Using the PCA of the experimental data, four components were determined with eigenvalues (i.e. the measure of the total variance in all variables which is accounted for by that component) equal to PC1 $=3.5308, \mathrm{PC} 2=0.3969$, PC3 $=0.0614$ and PC4 $=0.0111$. Thus, those consecutive components explain $88.3 \%, 9.9 \%, 1.5 \%$ and $0.3 \%$ of the total variance, respectively. It means that practically only the first two components should be considered. The two dimensional scatterplot presenting inter-sample relationships for these two components is shown in Figure 2(a). It is evident that the points for $\mathrm{Fe}, \mathrm{Al}$ and $\mathrm{Mg}$ (corresponding to the highest concentrations) are separated from the other six elements, which form one cluster in the plot. In order to explain the physical meaning of the first most important principal component, the plot of all the metal concentrations against the PC1 scores is shown in Figure 2(b). It is evident that points in the plot form two clusters along two lines of different slopes: one for the data of $X$. securis and another for the data of $M$. galloprovincialis. In each case, good linear correlations hold between metal concentrations and PC1 scores. For $X$. securis data, slopes are high (511 and 448) whereas for $M$. galloprovincialis they are much lower (52 and 55). Thus, it is evident that the concentration of 
metals in byssal threads depends mainly on the mussel species as described by PC1 in $88.3 \%$ and not by the site reflecting different environmental conditions. Other principal components do not describe the impact of the site either, as supported by similar plots. The same conclusion was obtained using the linear regression analysis. Results obtained for regressions of concentrations of nine metals for all samples from Table 1 are presented in Table 2. The slopes of regressions a (given with confidence intervals calculated from Student's distribution with a confidence level of 99\%) differ significantly. They are close to one for the analysis of samples of the same mytilid at different sites (entries 2 and 3). However, for the reverse situation (entry 1 in Table 2) the slope indicates that concentrations of metals in the byssus of $X$. securis are nine times higher than in samples of $M$. galloprovincialis from the same site SS. Note also that the highest residual standard deviation $\mathrm{Sy} / \mathrm{x}$ was observed for the last regression indicating the highest scatter of experimental points. All results obtained support a higher impact of the nature of the mytilid species on metal concentrations in threads than of the site of sample collection.

(a)

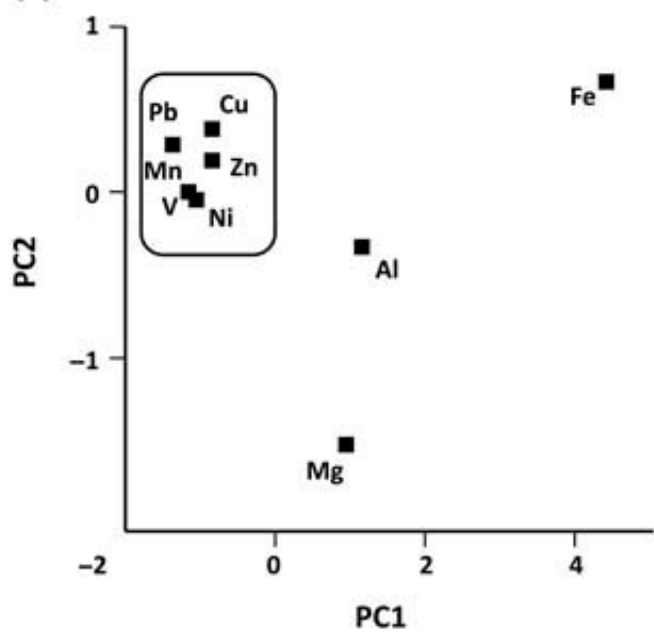

(b)

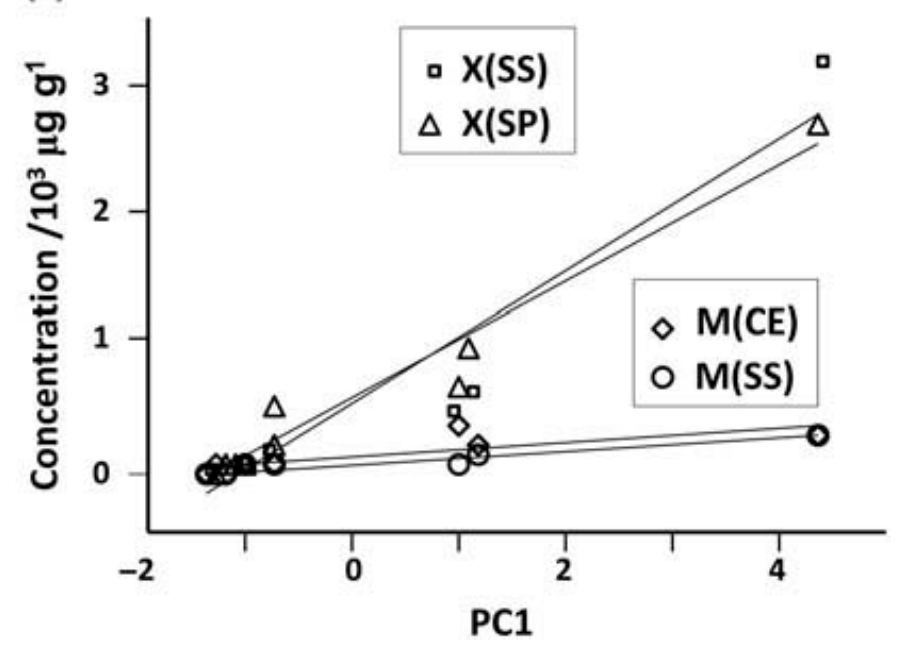

Figure 2. Results of PCA: (a) distribution of all elements in PC2 against PC1 space; (b) plot of metal concentrations in different samples against the PC1 scores. Lines of regressions are shown for each sample. Determination coefficients are equal to $\mathrm{R}_{2}=0.9169,0.9603,0.9556$ and 0.6978 for $\mathrm{X}(\mathrm{SS}), \mathrm{X}(\mathrm{SP}), \mathrm{M}(\mathrm{SS})$ and $\mathrm{M}(\mathrm{CE})$, respectively; for abbreviations, see Table 1.

\subsection{TEM images}

In our opinion, the discussed result can be related to a different structure of threads of both mytilids. Micrographs of M. galloprovincialis threads sectioned perpendicularly to the fibre 
axis showed a thin cuticle of granular microstructure [15-17] as is illustrated by the TEM image in Figure 3(a). Moreover, the localisation of iron and aluminium in the cuticle was experimentally proved by the energy-dispersive spectrometry [14], and the localisation of iron was proved by the secondary ion mass spectroscopy [16] and in situ resonance Raman spectroscopy [17]. The latter technique clearly revealed the existence of interactions between catechol and $\mathrm{Fe}^{+}$ions in granules of the cuticle. On the other hand, the TEM image of transverse cross section of the $X$. securis thread shown in Figure 3(b) shows a uniformly homogeneous interior and cuticle without any granular structure. If metal ions are bound in the thin cuticle of the thread of M. galloprovincialis, then their concentrations may be lower than those found in threads of $X$. securis. Moreover, specific interactions of particular metal ions with organic components of the threads, as observed for $\mathrm{Fe}^{+}$ions and catechol [17], must be taken into account in analytical methods used to evaluate contamination of the environment by heavy metals.

(a)

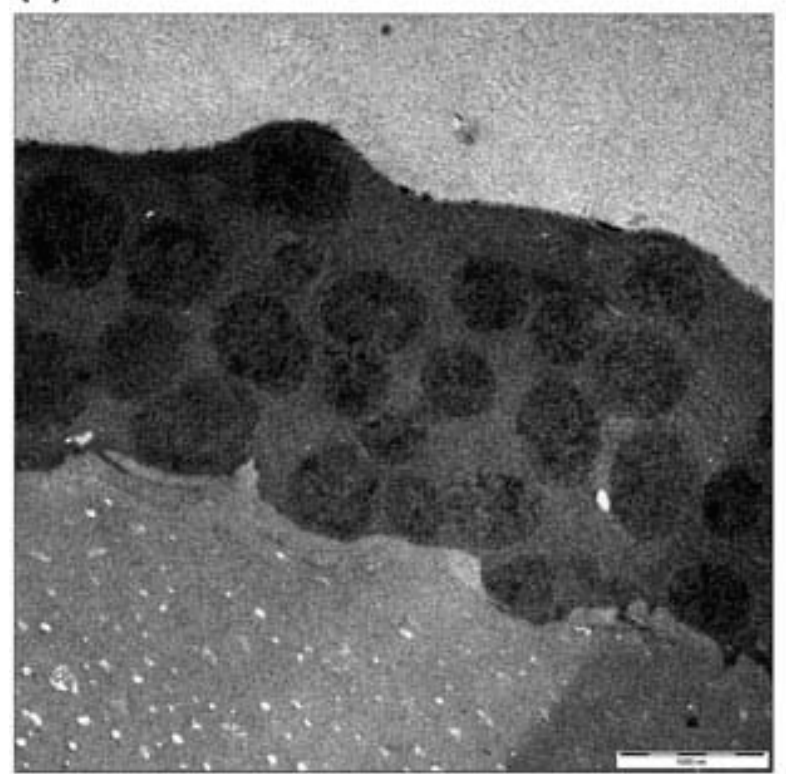

(b)

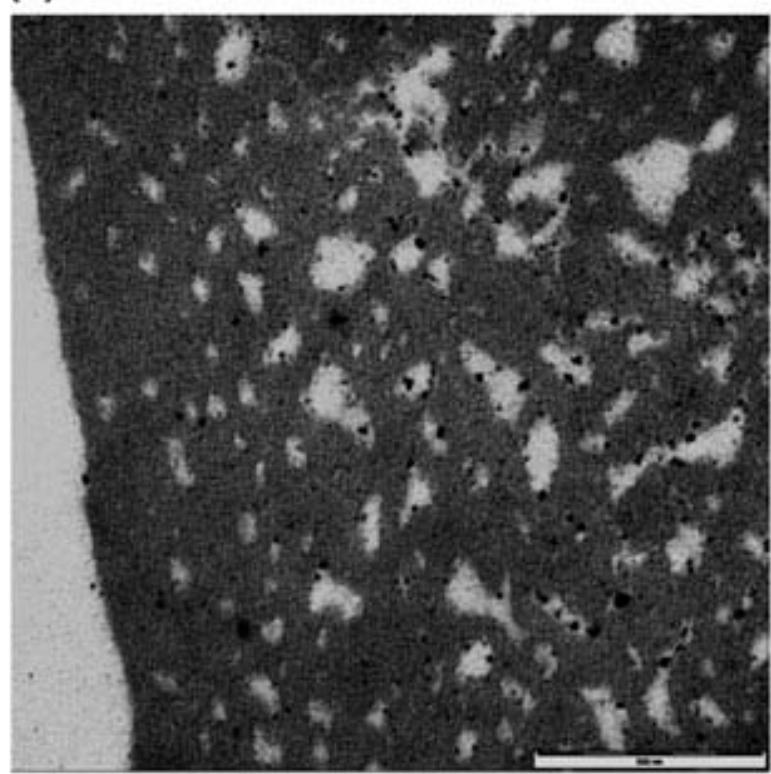

Figure 3. Transmission electron microscopy images of transverse cross-sections of threads from both mytilids. (a) M. galloprovincialis (32,000×) showing the granular cuticle above the thread interior; (b) $X$. securis $(100,000 \times)$ showing a homogeneous thread interior and cuticle. Bars are equal to (a) $1000 \mathrm{~nm}$; (b) $500 \mathrm{~nm}$.

\section{Conclusions}


Using the byssal threads as an example of environmental pollution biomarkers suggested in the analytical literature, it was shown that the effect of the nature of mytilid species, e.g. speciesspecific features, on metal concentrations is more important than the site of sample collection. The explanation for the higher concentrations of a number of metals in threads of $X$. securis than in those of $M$. galloprovincialis is proposed for the first time. In our opinion, this is due to different microstructures of threads, and thus, different ability to specifically bind particular metal ions. The above results should be taken into account during the complex analysis of environmental contaminations recommended by the 2008/56/EC Directive [19] because a similar situation may apply to other biomarkers.

\section{Acknowledgements}

We thank Julita Nowakowska at the Department of Biology, University of Warsaw, for preparing TEM images. JMFB also acknowledges E. Silva Caride for the technical assistance in the field and laboratory.

\section{Disclosure statement}

No potential conflict of interest was reported by the authors.

\section{Funding}

This study was partly funded by the project AGL2010-16464 (Ministerio de Ciencia e Innovación, Gobierno de España).

\section{References}

[1] E.I. Hamilton, Mar. Ecol. Prog. Ser. 2, 61 (1980). doi:10.3354/meps002061

[2] T.L. Coombs and P.J. Keller, Aqutic Toxicol. 1, 291 (1981). doi:10.1016/0166-445X(81)90023-0

[3] M. Koide, D.S. Lee and E.D. Goldberg, Estuar. Coast. Shelf Sci. 15, 679 (1982). doi:10.1016/02727714(82)90079-8

[4] P. Szefer, K. Frelek, K. Szefer, C.B. Lee, B.-S. Kim, J. Warzocha, I. Zdrojewska and T. Ciesielski, Environ. Pollut. 120, 423 (2002). doi:10.1016/S0269-7491(02)00111-2

[5] S. Nicholson and P. Szefer, Mar. Pollut. Bull. 46, 1040 (2003). doi:10.1016/S0025-326X(03)00152-8

[6] C.K. Yap, A. Ismail, S.G. Tan and H. Omar, Environ. Intern. 29, 521 (2003). doi:10.1016/S01604120(03)00008-4

[7] P. Szefer, B.-S. Kim, C.-K. Kim, E.H. Kim and C.-B. Lee, Environ. Pollut. 129, 209 (2004). doi:10.1016/j.envpol.2003.10.012

[8] C.K. Yap, A. Ismail and S.G. Tan, Russ. J. Mar. Biol. 31, 102 (2005). doi:10.1007/s11179-005-0050-5

[9] C.K. Yap, A. Ismail and S.G. Tan, Malaysian Appl. Biol. 34, 7 (2005).

[10] C.K. Yap, A. Ismail, W.H. Cheng, F.B. Edward and S.G. Tan, Malaysian Appl. Biol. 35, 7 (2006).

[11] P. Szefer, S.W. Fowler, K. Ikuta, F. Paez Osuna, A.A. Ali, B.-S. Kim, H.M. Fernandes, M.-J.

Belzunce, B. Guterstam, H. Kunzendorf, M. Wołowicz, H. Hummel and M. Deslous-Paoli, Environ. Pollut. 139, 70 (2006). doi:10.1016/j.envpol.2005.04.031

[12] S. Casas and C. Bacher, J. Sea Res. 56, 168 (2006). doi:10.1016/j.seares.2006.03.006 
[13] C.K. Yap and S.G. Tan, Indian J. Mar. Sci. 35, 227 (2007).

[14] C.J. Sun and J.H. Waite, J. Biol. Chem. 280, 39332 (2005). doi:10.1074/jbc.M508674200

[15] N. Holten-Andersen, G.E. Fantner, S. Hohlbauch, J.H. Waite and F.W. Zok, Nat. Mater. 6, 669 (2007). doi:10.1038/nmat1956

[16] N. Holten-Andersen, T.E. Mates, M.S. Toprak, G.D. Stucky, F.W. Zok and J.H. Waite, Langmuir 25, 3323 (2009). doi:10.1021/la8027012

[17] M.J. Harrington, A. Masic, N. Holten-Andersen, J.H. Waite and P. Fratzl, Science 328 (216), (2010). doi:10.1126/science.1181044.

[18] G. Blackmore and B. Morton, Mar. Pollut. Bull. 42, 1161 (2001). doi:10.1016/S0025-326X(01)

00132-1

[19] Directive 2008/56/EC The European Parliament and of the Council of 17 June 2008 on establishing a framework for community action in the field of marine environmental policy (Marine Strategy Framework Directive); Official J. European Union, L 164/19-L164/40 (2008).

[20] J.M.F. Babarro and E. Carrington, Mar. Ecol. Prog. Ser. 435, 125 (2011). doi:10.3354/meps09200

[21] J.M.F. Babarro and M. Lassudrie, Aquat. Living Resour. 24, 303 (2011). doi:10.1051/alr/2011142

[22] J.M.F. Babarro and M.J. Abad, Mar. Ecol. Prog. Ser. 476, 115 (2013). doi:10.3354/meps10122 
Table 1. Concentrations (in $\mu \mathrm{g} \mathrm{g}^{-1}$ of a sample dry mass) of 11 elements in samples of byssus threads of a different origin ${ }^{\mathrm{a}}$ and the concentrations ratio for samples of $X$. securis and M. galloprovincialis from San Simón.

\begin{tabular}{llllll}
\hline Element & $\begin{array}{l}\text { Concentration } \\
\text { X(SS) }\end{array}$ & M(SS) & X(SS)/M(SS) & X(SP) & M(CE) \\
& & & & & \\
& & 20 & 9.9 & 496 & 28 \\
${ }^{65} \mathrm{Cu}$ & 197 & 5 & 1.4 & 53 & 15 \\
${ }^{55} \mathrm{Mn}$ & 7 & 7 & - & $<\mathrm{LOQ}$ & 15 \\
${ }^{95} \mathrm{Mo}$ & $<\mathrm{LOQ}$ & 24 & 1.5 & 41 & 61 \\
${ }^{60} \mathrm{Ni}$ & 36 & 3 & 4 & 14 & 3 \\
${ }^{208} \mathrm{~Pb}$ & 12 & 48 & 4.0 & 223 & 43 \\
${ }^{66} \mathrm{Zn}$ & 191 & 294 & 10.7 & 2688 & 285 \\
${ }^{57} \mathrm{Fe}$ & 3133 & 93 & 5.3 & 666 & 330 \\
${ }^{26} \mathrm{Mg}$ & 490 & 180 & 3.6 & 951 & 190 \\
${ }^{27} \mathrm{Al}$ & 640 & $<\mathrm{LOQ}$ & - & 13 & 19 \\
${ }^{88} \mathrm{Sr}$ & 8 & 20 & 1.6 & 31 & 53 \\
${ }^{51} \mathrm{~V}$ & 31 & & & &
\end{tabular}

Notes: $\mathrm{X}(\mathrm{SS})$ byssus of $X$. securis from San Simón; X(SP) byssus of $X$. securis from Sampaio; M(SS) byssus of M. galloprovincialis from San Simón; M(CE) byssus of M. galloprovincialis from Cabo Estay.

Table 2. Analysis of linear regressions $\mathrm{C}_{\mathrm{y}}=a \mathrm{C}_{\mathrm{x}}+b$ between concentrations of elements determined in byssus of different samples

\begin{tabular}{cccccccc}
\hline No. & $\mathrm{C}_{\mathrm{y}}$ & $\mathrm{C}_{\mathrm{x}}$ & $a$ & $b$ & $\mathrm{R}^{2}$ & $\mathrm{~F}$ & $\mathrm{~S}_{\mathrm{y} / \mathrm{x}}$ \\
\hline 1 & $\mathrm{X}(\mathrm{SS})$ & $\mathrm{M}(\mathrm{SS})$ & $9.3 \pm 5.1$ & $-186 \pm 621$ & 0.8520 & 40.29 & 412.6 \\
2 & $\mathrm{X}(\mathrm{SS})$ & $\mathrm{X}(\mathrm{SP})$ & $1.2 \pm 0.3$ & $-132 \pm 281$ & 0.9664 & 201.5 & 196.5 \\
3 & $\mathrm{M}(\mathrm{SS})$ & $\mathrm{M}(\mathrm{CE})^{\mathrm{a}}$ & $0.9 \pm 0.1$ & $14.6 \pm 14.5$ & 0.9783 & 315.8 & 17.1 \\
\hline
\end{tabular}

Notes: X(SS), X(SP), M(SS) and M(CE) - see Table $1 ; \mathrm{R}^{2}$, the determination coefficient; $\mathrm{F}$, the Snedecor test; $\mathrm{S}_{\mathrm{y} / \mathrm{x}}$, the residual standard deviation.

${ }^{\mathrm{a}}$ Mo is included instead of the most deviating point for Mg. 